\title{
Comparison on depollution capabilities of two iron based magnetic nanopowders
}

\author{
Cristian Pantilimon ${ }^{1}$, Andra Predescu $^{1 *}$, Ruxandra Vidu ${ }^{2}$, Ecaterina $^{*}$ Matei $^{1}$ \\ and Cristian Predescu ${ }^{1}$ \\ ${ }^{1}$ University Politehnica, Centre for Research and Eco-Metallurgical Expertise, 060042, \\ Bucharest, Romania \\ ${ }^{2}$ University of California Davis, Department of Chemical Engineering and Materials \\ Science, Davis, CA 95621, USA \\ *e-mail: andra.predescu@ecomet.pub.ro
}

\begin{abstract}
:
Removal of toxic metals from waste waters is one of the main concerns for environmental protection due to the high toxicity combined with their very long life span and slow biodegradability. Heavy metals such as $\mathrm{Cr}$ (VI) are very hazardous to the health of humans, flora and fauna because once they are absorbed into a living organism they are eliminated very slowly and become part of the food chain. The removal of such toxic materials has been tested through the use of magnetic nanoparticles in order to obtain a clean depollution of waste water. The comparison of two such materials, magnetite and maghemite was presented. The synthesis procedure for both materials was compared, their morphologies analyzed by XRD, TEM and SAED and their adsorption capabilities were evaluated at various $\mathrm{pH}$ values. The purpose of this study was to determine the differences in performance of the two magnetic nanopowders in terms of $\mathrm{Cr}$ (VI) removal from waste waters.
\end{abstract}

\section{Introduction}

The removal of toxic metals from waste waters has been an important subject for environmental protection due to their high toxicity to both natural and anthropic environments. Most of these metals are not biodegradable and because of their long lifespan and the possibility of accumulation in living organisms they may cause various diseases and disorders, becoming a risk to both the environment and human health [1]. For these reasons, the removal of metals such as $\mathrm{Cd}, \mathrm{Cr}, \mathrm{Ni}$, and $\mathrm{Cu}$ has been researched in order to improve the water purification techniques.

Several removal methods have been documented such as adsorption, chemical precipitation, ion exchange, filtration, membrane separation and reverse osmosis $[2,3]$. Due to the developments in nanotechnology, nanomaterials have been tested for the removal of heavy metals from waters because of their high specific surface area and adsorption capabilities. Magnetic Fe oxide nanoparticles show promise as an efficient material for removing metal pollutants and a high possibility of re-use through magnetic separation with ion exchange [4]. The synthesis of such magnetic nanoparticles can be done through various methods including: co-precipitation, solgel synthesis, sonochemical reactions, hydrothermal reactions, flow injection synthesis and electrospray synthesis [4].

The adsorption properties of the materials are directly connected to the particle size and the specific surface area of the powders. A high 
specific surface area leads to an increase in adsorption.

In this study, a comparison is made between the adsorption properties of 2 magnetic nanomaterials, Magnetite $\left(\mathrm{Fe}_{3} \mathrm{O}_{4}\right)$ and Maghemite $\left(\gamma-\mathrm{Fe}_{2} \mathrm{O}_{3}\right)$, and their specific morphologies for a better understanding as to how the adsorption properties of the materials vary in various conditions. The heavy metal studied for removal is $\mathrm{Cr}$ (VI).

The adsorbents were obtained through coprecipitation and they were characterized by XRay Diffraction (XRD), Transmission Electron Microscopy (TEM) and Selected Area Electron Diffraction (SAED). After being submersed in waters polluted with $\mathrm{Cd}$ and $\mathrm{Cr}$, the nanomaterials were washed and the resulting solutions were tested using a molecular absorption spectrometer and an atomic absorption spectrometer. The separation of the magnetic particles from the solution was performed using an external magnetic field.

\section{Experimental Procedure}

\subsection{Synthesis of iron based nanoparticles}

The synthesis method used to obtain the magnetite is the conventional coprecipitation method. Commercial reagents with pure analytical grade were selected as precursors. $0.4 \mathrm{~mol} / \mathrm{L}$ $\mathrm{Fe}\left(\mathrm{NO}_{3}\right)_{3} \times 9 \mathrm{H}_{2} \mathrm{O}$ and $0.4 \mathrm{~mol} / \mathrm{L} \mathrm{FeCl}_{2} \times 9 \mathrm{H}_{2} \mathrm{O}$ were mixed at a molar ratio of $1: 2$ in the presence of 0.5 $\mathrm{mol} / \mathrm{L} \mathrm{NaOH}$ in distilled water at room temperature. The $\mathrm{pH}$ of the solution was maintained at 10 for $3 \mathrm{~h}$, after which the precipitate was separated by centrifugation and washed several times with distilled water until the $\mathrm{pH}$ becomes 7 [6]. In order to prevent agglomeration of the particles, D-sorbitol was added to the solution. [7]

After washing, the magnetite particles were dried in an oven at $60^{\circ} \mathrm{C}$. Part of the magnetite was separated and used to obtain maghemite. The procedure involves heating the magnetite at $200^{\circ} \mathrm{C}$ for 3 hours. After this the precipitate presents a red-brown color, as opposed to completely black, which represents the maghemite formation [8].

\subsection{Adsorbent characterization}

The crystalline structure was analyzed by X-ray diffraction (XRD) at room temperature using a Panalytical X'PERT MPD equipped with a copper anode which generates $\mathrm{Cu} \mathrm{K} \alpha$ radiation $(\lambda=$ $1.54065 \AA$ ) with a $2 \theta$ scanning range of $10^{\circ}$ to $90^{\circ}$. The particle size and distribution were determined by high resolution transmission electron microscopy (HRTEM). The analysis procedure involved mixing the samples in ethanol, ultrasonication and placement on carbon grids. The samples were analyzed with a TECNAI F30 $\mathrm{G}^{2}$ transmission electron microscope. The iron based particles were also analyzed by selected area electron diffraction (SAED) [8].

\subsection{Adsorption experiments}

The $\mathrm{Cr}(\mathrm{VI})$ solution was prepared by dissolving $\mathrm{K}_{2} \mathrm{CrO}_{4}$ into ultrapure water. The $\mathrm{pH}$ of the solution was adjusted by using solutions of $\mathrm{HCl}$ $(0.1 \mathrm{~N})$ and $\mathrm{NaOH}(0.1 \mathrm{~N})$. The adsorption studies were performed by measuring the initial and final concentrations of the metal with a GBC $932 \mathrm{AB}$ Plus spectrometer (flame atomic absorption spectrometry) with spectral domain between 185 and 900nm. For the $\mathrm{Cr}$ (VI) solution analysis, a Cintra 202 GBC spectrophotometer, with spectral domain between 190 and $1000 \mathrm{~nm}$ was used. [6]

The removal efficiency was calculated based on the formula [9]:

$$
\eta=100 x\left(\mathrm{C}_{0}-\mathrm{C}_{\mathrm{e}}\right) / \mathrm{C}_{0}
$$

where $C_{0}$ is the initial concentration $(\mathrm{mg} / \mathrm{L})$ and $C_{e}$ is the equilibrium concentration $(\mathrm{mg} / \mathrm{L})$.

The adsorbed metal amount at equilibrium is expressed as $q_{c}$ [4]:

$$
\mathrm{q}_{\mathrm{c}}=\left(\mathrm{C}_{0}-\mathrm{C}_{\mathrm{e}}\right) \mathrm{V} / \mathrm{m}
$$

where $V$ is the solution volume (L), and $m$ is the adsorbent quantity (g). 
The quantity of adsorbents used was $0.1 \mathrm{~g}$ and the concentrations of metal ions in the synthetic solutions that were tested were selected as 40 and $50 \mathrm{mg} / \mathrm{L}$ [6].

\section{Results and Discussion}

\subsection{Characterization of the iron based nanoparticles}

The XRD patterns of the powders can be observed in Figure 1. The XRD analysis of the two magnetic nanopowders reveals that the patterns are quite similar. At a closer look, the main differences that can be observed are the variation in peak intensities and the positions of the peaks. In this case the maghemite shows lower intensity than the magnetite.
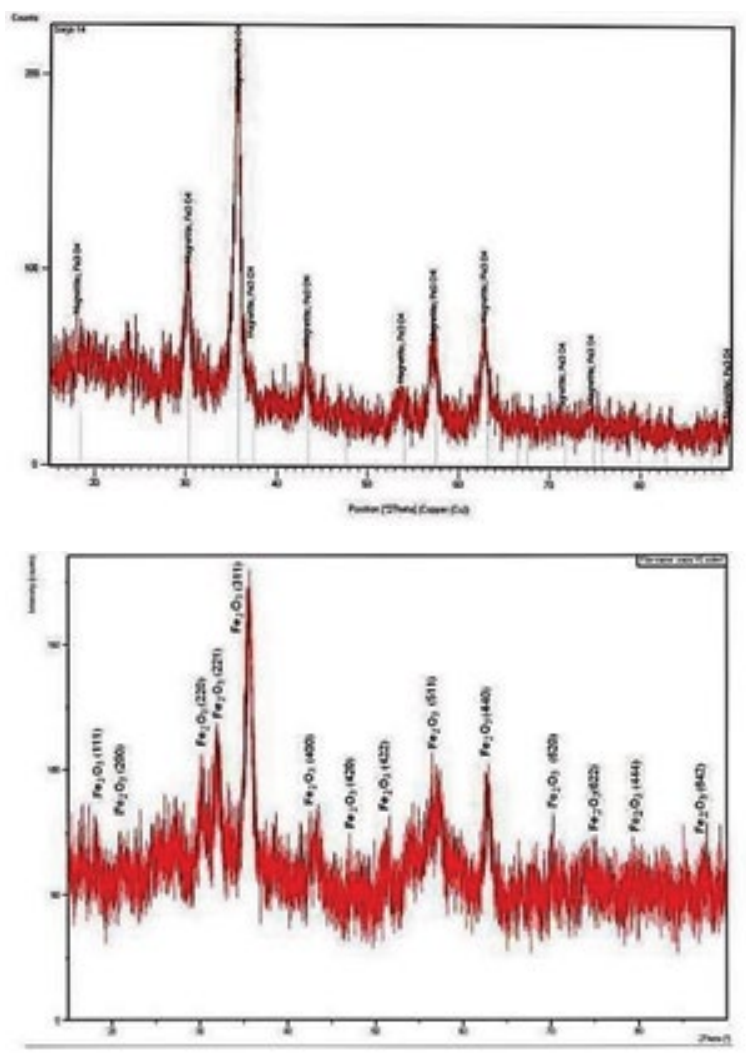

Figure 1. XRD patterns of synthesized magnetite (top) and maghemite (bottom)
The powder morphology was analyzed by transmission electron microscopy, combined with selected area electron diffraction, in order to evaluate the size and the shape of the particles, as well as the structure. Figure 2 shows TEM images of $\mathrm{Fe}_{3} \mathrm{O}_{4}$ and $\gamma-\mathrm{Fe}_{2} \mathrm{O}_{3}$. Both particles show high sphericity and appear to be nanosized.
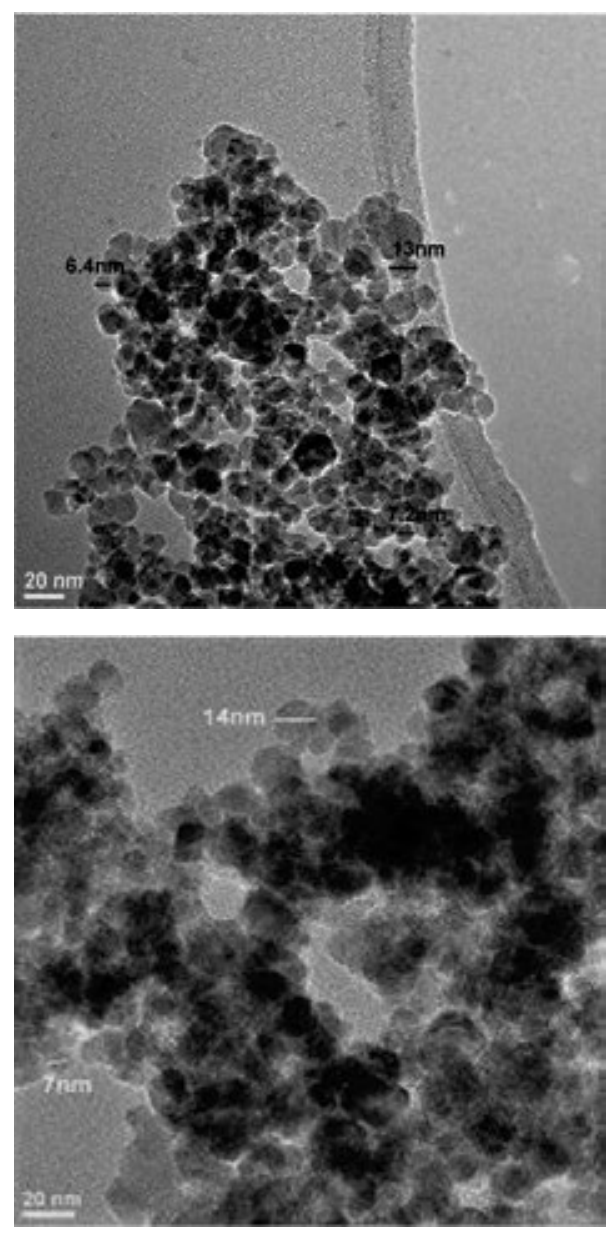

Fig. 2. TEM images of $\mathrm{Fe}_{3} \mathrm{O}_{4}$ (top) and $\gamma-\mathrm{Fe}_{2} \mathrm{O}_{3}$ (bottom)

The nano-scale characteristic of the particles is also demonstrated through the SAED analysis, which displays a ring pattern specific to nanoparticles. Due to the heat treatment applied to magnetite to obtain maghemite, the particles show a small increase in size compared to magnetite, but 
they maintained the nano-size feature. The SAED analysis associated with the TEM images are presented in Figure 3.
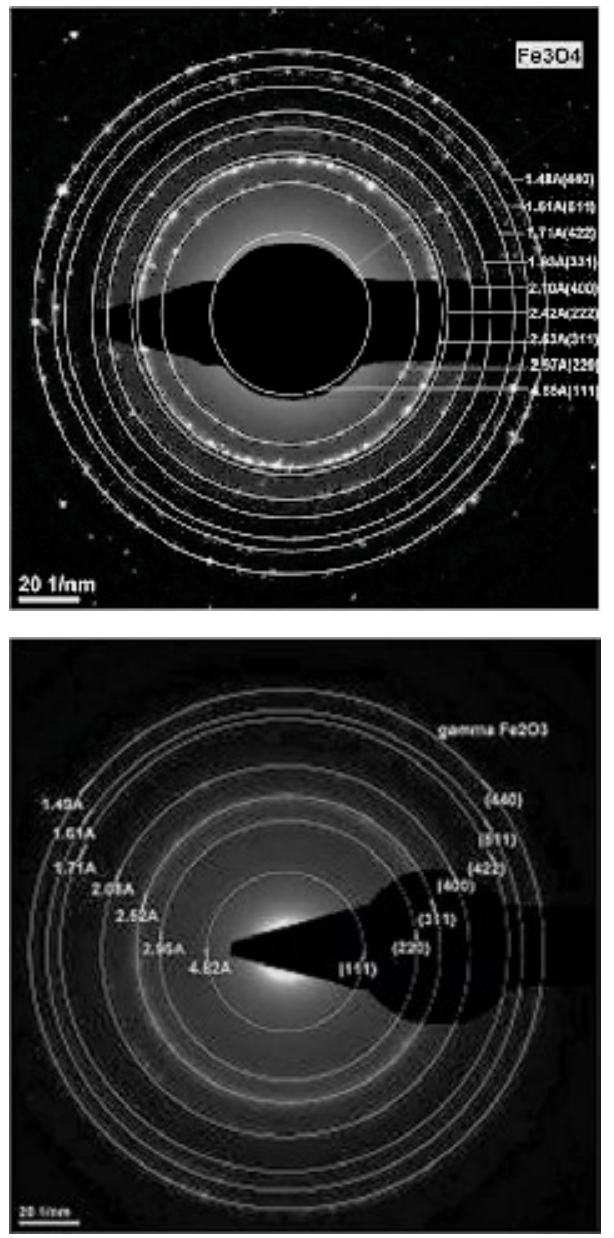

Fig. 3. SAED images of $\mathrm{Fe}_{3} \mathrm{O}_{4}$ (top) and $\gamma-\mathrm{Fe}_{2} \mathrm{O}_{3}$ (bottom)

\subsection{Adsorption capabilities}

The main purpose of this study is to compare the adsorption capacities of magnetite and maghemite particles, previously characterized, in order to obtain a better understanding of the influence of various factors that may have over the depollution properties of the magnetic powders.

The adsorption tests involve the use of $0.1 \mathrm{~g}$ of each magnetic powder, $\mathrm{Fe}_{3} \mathrm{O}_{4}$ and $\gamma-\mathrm{Fe}_{2} \mathrm{O}_{3}$ combined with $50 \mathrm{mg} / \mathrm{L}$ and $40 \mathrm{mg} / \mathrm{L}$ solution of Cr (VI) respectively [7, 10].

The removal efficiency of the magnetic powders was calculated every 10 minutes for 100 minutes at various $\mathrm{pH}$ values and it was tested for various $\mathrm{pH}$ values $[7,10]$. The results of this analysis is presented in Figure 4.
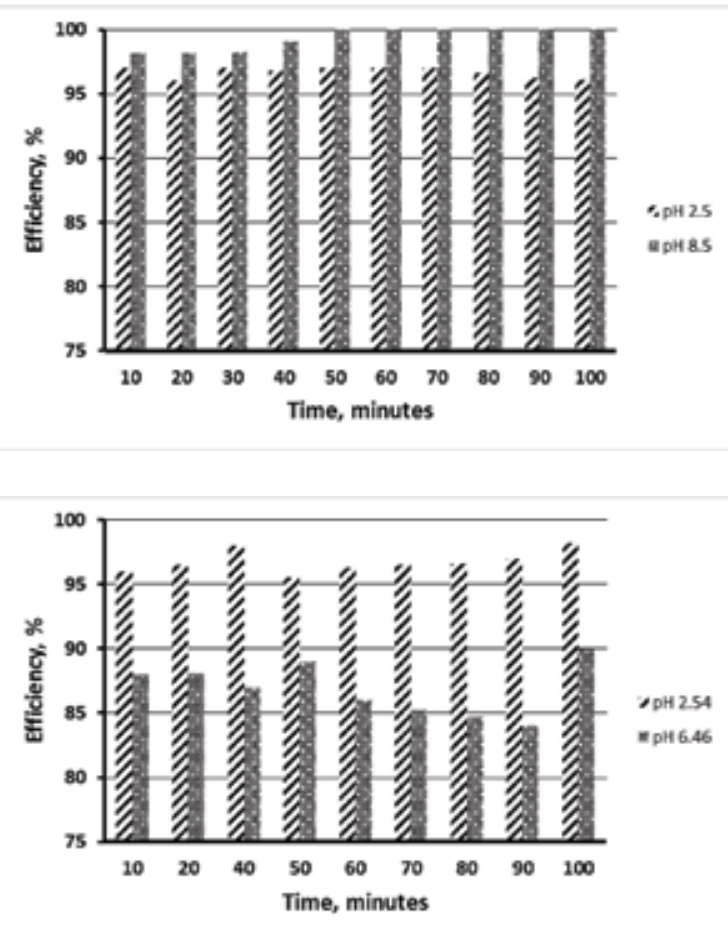

Fig. 4. Removal efficiency for $\mathrm{Fe}_{3} \mathrm{O}_{4}$ (top) and $\gamma$ $\mathrm{Fe}_{2} \mathrm{O}_{3}$ (bottom) at various $\mathrm{pH}$ values

As can be observed in Fig. 4, the magnetite displays a higher removal efficiency when used in a more basic environment, but even in the solution with $\mathrm{pH} 2.5$ it shows a high capacity for $\mathrm{Cr}$ adsorption. In the case of the maghemite, increasing the $\mathrm{pH}$ of the solution to a neutral standpoint leads to the decrease of efficiency to under $90 \%$. Comparing the results of the two solutions for adsorption in acid environment it can be seen that the maghemite displays a slightly 
higher removal efficiency than the magnetite, but the magnetite shows a high stability in removal.

The magnetite has also been tested for removal of $\mathrm{Cd}, \mathrm{Ni}$ and $\mathrm{Cu}$, under the same conditions as the $\mathrm{Cr}$ (VI), the results showing that the removal efficiency after 10 minutes of the magnetite in solutions with $\mathrm{pH} 2.5$ follows the order $\mathrm{Cr}>\mathrm{Ni}>\mathrm{Cd}>\mathrm{Cu}$, while in the case of using a $\mathrm{pH}$ of 8.5 the order changes to $\mathrm{Ni}>\mathrm{Cr}>\mathrm{Cu}>\mathrm{Cd}$. [10].

In case of the amount adsorbed at equilibrium, $\mathrm{q}_{\mathrm{e}}$, the magnetite shows a value of $48.5 \mathrm{mg} / \mathrm{g}$ at $\mathrm{pH}$ 2.5 and $0.59 \mathrm{mg} / \mathrm{g}$ at $\mathrm{pH} 8.5$ after $\mathrm{NaOH}$ precipitation [10]. The maghemite displays a $\mathrm{q}_{\mathrm{e}}$ value of $19.16 \mathrm{mg} / \mathrm{g}$ at $\mathrm{pH} 2.54$ and $17.85 \mathrm{mg} / \mathrm{g}$ at pH 6.46 after 10 minutes [7].

\section{Conclusions}

Both magnetite and maghemite display high removal efficiencies for the depollution of $\mathrm{Cr}$ from waste waters at various $\mathrm{pH}$ values. The usefulness of the iron based magnetic nanoparticles also comes from their small sizes combined with high specific surface areas and due to the possibility of recovery of the materials and reuse. In the case of magnetite, the $\mathrm{pH}$ variation did not have a high impact as in the case of the maghemite. Both magnetic nanopowders may be used for the removal of heavy metals from synthetic solutions.

\section{References}

1) C. Balan, C. Cojocaru, P. Bulai, D. Bilba, M. Macoveanu, Environmental Engineering and Management Journal, 8 (2009), 225.
2) C. Modrogan, D.G. Apostol, O.D. Butucea, A.R. Miron, C. Costache, R. Kouachi, Environmental Engineering and Management Journal, 12 (2013), 929.

3) A. Valipour, S.M. Taghvaei, V.K. Raman, G.B. Gholikandi, S. Jamshidi, N. Hamnabard, Environmental Engineering and Management Journal, 13 (2014), 145.

4) X. Wang, C. Zhao, P. Zhao, P. Dou, Y. Ding, P. Xu, Bioresources Technology, 100 (2009), 2301.

5) Y.F. Shen, J. Tang, Z.H. Nie, Y.D. Wang, Y. Ren, L. Zuo, Separation and Purification Technology, 68 (2009), 312.

6) E. Matei, A.M. Predescu, C. Predescu, M.G. Sohaciu, A. Berbecaru, C.I. Covaliu, Journal of Environmental Quality, 42 (2013), 129.

7) E. Matei, A.M. Predescu, A. Predescu, E. Vasile, Environmental Engineering and Management Journal, 10 (2011), 1711.

8) E. Matei, A. Predescu, E. Vasile, A. Predescu, Journal of Physics: Conference Series, 304 (2011), 012022.

9) M. Ozmen,, K. Can, G. Arslan, A. Tor, Y. Cengeloglu, and M. Ersoz, Desalination, 254 (2010), 162.

10) E. Matei, C. Predescu, A. Badanoiu, A. Predescu, D. Ficai, Environmental Engineering and Management Journal, 14 (2015), 1001. 